\title{
PALESTRA:
}

\section{Propostas de educação musical no Rio Grande do Sul 1977, 1978 e 1981}

\author{
Leda de A. Maffioletti
}

O objetivo deste trabalho é analisar algumas iniciativas da Secretaria de Educação do Rio Grande do Sul relativas à construção de propostas curriculares, programas de ensino ou seminários realizados em prol da Educação Musical no Estado. Não pretende fazer qualquer crítica à linha teórica ou tipo de orientação defendida, mas reflete uma preocupação em conhecer aquilo que, em algum momento histórico, foi preocupação do Estado junto às escolas da rede pública. A análise limita-se a pesquisa em documentos de origem pessoal cedido por professores que vivenciaram a aplicação dessas orientações, uma vez que não há, no presente momento, um registro oficial sobre as atividades de assessoramento, distribuição de materiais ou outro documento cadastrado na Secretaria de Educação, que pudesse servir de apoio para uma pesquisa mais aprofundada.

Foram tomados para estudo os seguintes documentos: “Educação Artística/Música - 
Caderno de Orientação" SEC 1977; Seminário Permanente de Orientação ao Ensino - SPOE. Educação Artística/ Estrutura da Educação Musical" SEC/1 $1^{\text {a }}$ DE (1978); "Projeto Especial: Desenvolvimento Integrado da Arte na Educação - PRODIARTE - Subsídio de Orientação 2" - SEC 1981; "Projeto Melhoria da Qualidade de Ensino - Educação Artística 1 e 2 graus” - SEC 1993.

Com o objetivo de compreender melhor os documentos, inicialmente procuro identificar os objetivos que justificaram sua criação ou elaboração. Em seguida observo a forma como o documento foi estruturado e os conteúdos musicais veiculados. Para encerrar faço um breve comentário sobre o estudo realizado e indico outros caminhos para uma pesquisa mais aprofundada sobre $o$ assunto.

\section{Educação Artística - Cadernos de Orientação - SEC/RS 1978}

Este caderno de orientações tem por finalidade "oferecer material de apoio ao professor de Educação Artística em sua ação docente" (p.1). Pretende auxiliar o professor na sua tarefa de "sensibilizar a aluno para a arte, através do desenvolvimento de seu potencial criador, contribuindo para torná-lo um ser dotado de senso estético e, para o qual, a arte venha a se constituir em um valor permanente" (p.1) 
$\mathrm{Na}$ apresentação do documento, a arte é considerada um meio de comunicação e expressão, geradora e transmissora de cultura e a melhor maneira de realizar a experiência criadora. Por esse motivo a Educação Artística deve fazer parte da formação geral dos alunos, proporcionando condições para que ele conheça melhor a si mesmo, o mundo em que vive e a cultura à qual pertence. Como objetivo geral da Arte, o documento defende o desenvolvimento da criatividade e a capacidade de apreciação artística. Como objetivo específico sugere ao professor proporcionar a seus alunos condições para desenvolver a capacidade de observar e apreciar, auto-expressar-se, sensibilidade artística, habilidade sensório-motoras, (...) "habilidades e hábitos necessários à aprendizagens futuras, capacidade para apreender o significado da arte através dos tempos" (p. 13) e outros tantos objetivos visando a formação geral da criança.

Nas considerações gerais o documento reconhece a insuficiência de professores especializados em Educação Artística, necessitando muitas vezes que o professor especializado exerça a função de orientar colegas de outras áreas. Visando essa situação, o documento também pretendo subsidiar os professores na realização dessas atividades.

Procurando abordar aspectos referentes ao professor e ao aluno, o documento faz referência ao aluno futuro professor - o aluno de magistério, defendendo para a sua formação, 
além dos conteúdos referidos no documento em questão, conhecimentos de psicologia evolutiva, etapas do desenvolvimento da psicomotricidade e as etapas da evolução do grafismo infantil.

Em continuidade, o documento apresenta sugestões de atividades nas áreas de Educação Plástica, Educação Dramática e Educação Musical. A parte de Educação Musical apresenta orientações gerais ao professor e sugestões de atividades. Como procedimento geral, o documento sugere que seja oferecido ao aluno oportunidades para expressar e criar suas próprias melodias, quadrinhas e outras produções musicais desde os primeiros contatos com a música. Para as atividades perceptivas, a orientação geral sugere partir da observação da natureza e meio ambiente; para as atividades de ritmo propõe a exploração dos movimentos básicos de andar, correr e saltar em andamentos diversos. Também a partir do movimento é sugerido introduzir noções de compasso a partir da percepção de acentuações e movimentos corporais. As canções e frases rítmicas poderão servir como forma de atividades de livre expressão e os trabalhos sobre os elementos do ritmo - tempo, compasso, subdivisão dos tempos. Paralelamente, o documento sugere também o uso de grafias para que o aluno "processe a compreensão e a fixação dessas aprendizagens” (p. 36)

As orientações gerais do Caderno não estão organizadas em áreas específicas do desenvolvimento musical. Para os tantos 
aspectos da teoria musical: dinâmica, fraseado, escalas, harmonia, escrita musical e prática instrumental ou vocal, as sugestões são acompanhadas de como se deve realizar as atividades, informando quando necessário, dos pré-requisitos para o seu desenvolvimento com sucesso. Sugere, por exemplo, que o reconhecimento dos intervalos seja feito inicialmente a partir da identificação desses intervalos em canções conhecidas, posteriormente sua localização na escala musical.

Sem formar um item à parte, as orientações definem o que consideram ser um Coral e como ele deve ser organizado; uma Banda Rítmica, como formar e quais objetivos deve enfocar. Nesse item, o documento defende como atividade necessária a exploração e pesquisa de sons, criação de partituras e confecção de instrumentos. Faz recomendações sobre a inclusão de música de diferentes estilos.

As sugestões de atividades formam uma lista bastante ampla de sugestões organizadas de forma sequencial, procurando atender 0 desenvolvimento musical evidenciado pelo aluno. Observa-se que as atividades iniciais são dedicadas à observação, exploração e criação de sons, frases e jogos rítmicos e melódicos. Seguem as atividades de exploração do espaço e movimentação corporal. Dando continuidade, apresenta sugestões de vivências dos valores musicais, canções em diferentes compassos e execução de instrumentos musicais. As 
atividades

perceptivas

envolvem

reconhecimento do movimento sonoro e gradativo reconhecimento de pequenos detalhes da formação das melodias. As atividades gráficas formam a sequência que inicia com a vivência corporal e reconhecimento auditivo da unidade de tempo e dos valores musicais. Outros aspectos da teoria musical já mencionados são desmembrados em atividades elementares e mais elaboradas, formando uma sequência de conteúdos a serem desenvolvidos, sem indicação de idade, série ou nível de ensino. Há, como foi descrito, a orientação geral de que seja respeitado o crescimento musical dos alunos. Essa recomendação é constante, estando presente ao se tratar, por exemplo, da noção de ritmo e compasso, ou na grafia musical, como se pode constatar nas páginas 36-37 e 38 respectivamente.

No final do documento consta uma ampla bibliografia geral de Artes, onde se observa várias obras específicas da área da música. Entre elas estão presentes três obras de Edgar Willems - sobre método de ensino da música (1961 a e b; 1962); Compagnon e Thomet - sobre a obra de Dalcroze (1966); Emília Jannibelli (1971) e Maria Augusta Joppert (1967) - ambas tratando da música na escola; Maria Aparecida Mahle na área da iniciação musical. Além de Kurt Pahlen (1965) constam outras obras mais teóricas sobre história da música e Folclore. Há também obras em edição espanhola de autores bastante divulgados no Brasil. 


\section{Seminário Permanente de Orientação ao Ensino - SPOE. Educação Artística: \\ Estrutura de Educação Musical}

\section{Porto Alegre/Junho/ 1978}

O documento não expõe os objetivos de sua elaboração, mas a temática única abordada e a bibliografia com citação apenas da obra de Michaelis sugere pensar que trata-se de um estudo a partir da obra desse autor. Inicia com a definição de "estrutura" como "um todo articulado, cujos elementos se relacionam de maneira constante e independente" (p. 1). "Modelo de estrutura é algo que o investigador elabora para tornar compreensível a estrutura; é uma apresentação simplificada da realidade; revela algum das conexões fundamentais da disciplina”. (p. 1)

0 estudo considera como disciplinas que servem de fundamento para a Educação Musical: Física, Física Aplicada, Antropologia, Etnomusicologia, Musicologia e Psicologia.

O Seminário de Estudos apresenta a estrutura da matéria "Música" representada num diagrama em forma de círculos concêntricos. A área formada pelo círculo maior representa a Música, englobando todos os outros elementos do diagrama. Seguindo a ordem decrescente na dimensão dos círculos, as Variações da Dinâmica, os elementos Ritmo, Melodia e Harmonia e como matéria prima, no centro do círculo, o Som. 
Para compreender melhor as intenções desse Seminário de Estudos, gostaria de mencionar que o Laboratório de Metodologia e Currículo da Faculdade de Educação da UFRGS, em parceria com o MEC e DEC, obteve grande impacto no meio educacional ao publicar 1976 "Cadernos de Metodologia - Comunicação e Expressão". Tratava-se de um estudo sobre a Natureza e Estrutura das diferentes disciplinas, com a finalidade de identificar as linhas metodológicas e o processo de integração intrínseca à área de Comunicação e Expressão. Este trabalho definiu as competências específicas para as diferentes áreas, apontando para a área da música as competências básicas como sendo: ouvir, reproduzir, improvisar, interpretar e apreciar. Em cada uma dessas competências, as habilidades para identificar, discriminar, classificar, recriar, inventar, analisar e avaliar foram devidamente graduadas.

O Seminário de Estudos realizado em 1978 em Porto Alegre, já mostra o empenho da Secretaria de Educação do RS em incentivar estudos nessa linha. Para se ter uma idéia da importância de tais estudos, gostaria de mencionar, também, que em 1979 o Conselho Estadual de Educação do Rio Grande do Sul emite o parecer $\mathrm{n}^{\circ} 179$ - que estabelece as diretrizes para o desenvolvimento da Educação Artística nas escolas de $1^{\circ}$ e $2^{\circ}$ graus do sistema estadual de ensino - inclui, como Anexo II, as Competências Específicas às áreas de Educação Artística, retiradas dos "Cadernos de Metodologia" acima referidos. Esse parecer do 
CEE definiu a situação da Educação Artística e subsidiou os Planos de Ensino em escolas da rede pública e particular.

Complementando os estudos, o Seminário apresenta as Etapas de um Programa de Educação Musical, no qual a formação da musicalidade seria garantida através de experiências em três modalidades de atividade musical: Audição, Execução e Composição. A seguir apresento um mapeamento do trabalho de Educação Musical implementado pela Secretaria de Educação do RS em 1978, cujo conteúdo foi retomado mais tarde no Projeto PRODIARTE. Trata-se de um estudo que toma por base a obra de John Michaelis e Ruth Grossman "Nuevos deseños para el curriculo de la escuela elemental" em edição mexicana de 1974, capítulo XII sobre Educação Musical. 


\section{ETAPAS DE UM PROGRAMA DE EDUCAÇÃO MUSICAL}

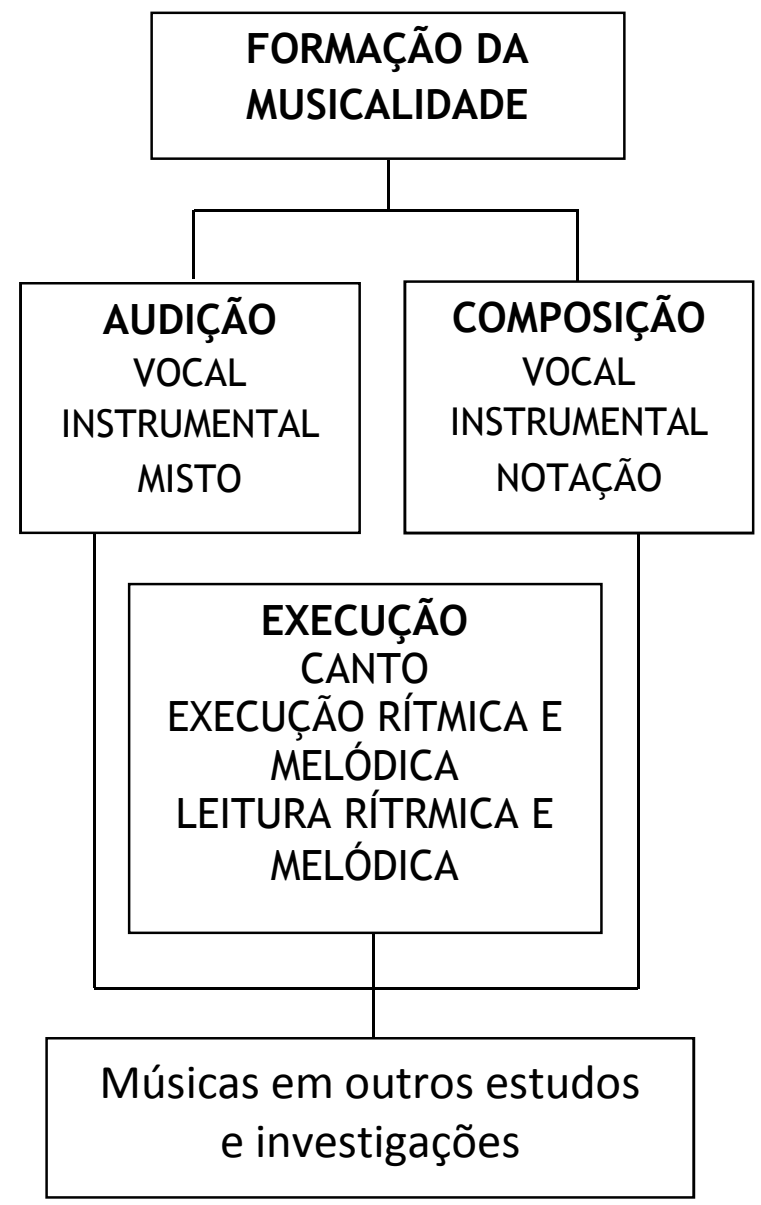

Fonte: Seminário Permanente de Orientação ao Ensino SPOE Educação Artística: Estrutura de Educação Musical Porto Alegre/Junho/ 1978 
ELEMENTOS BÁSICOS DA MÚSICA

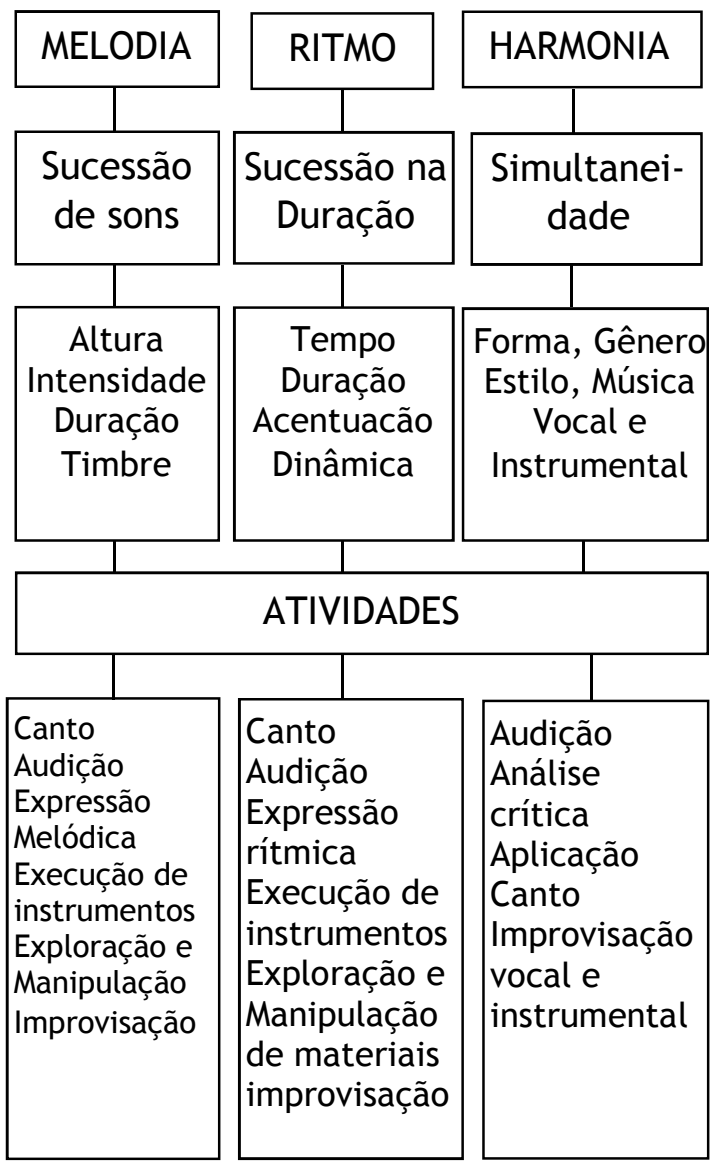

Fonte: Seminário Permanente de Orientação ao Ensino SPOE

Educação Artística: Estrutura de Educação Musical Porto Alegre/Juho/ 1978 


\section{Projeto Especial: Desenvolvimento Integrado da Arte na Educação. PRODIARTE. Subsídio de Orientação $\mathrm{n}^{\circ} 2$ SEC/RS 1981}

O documento PRODIARTE (1981) foi elaborado com o objetivo de "possibilitar ao professor regente de classe a identificação e o desenvolvimento de diferentes manifestações de arte e artesanato, entendidos como fatores impulsores para 0 alcance dos objetivos propostos no Currículo Pleno no Ensino de $1^{\circ}$ Grau" (p. 1). Com esse documento, o Departamento de Educação Fundamental "espera que seu uso auxilie os professores na manutenção do ensino vivo e dinâmico, capaz de contribuir para o desenvolvimento integral, criador e estético da criança - preocupação essencial e intrínseca à própria finalidade da Escola" (p.1).

O subsídio $\mathrm{n}^{\circ} 2$ compreende duas partes: parte I dedicada ao Teatro de Bonecos e parte II sugerindo atividades de Música. Na parte de teatro de Bonecos, o material pretende servir de apoio ao professor nas atividades de Educação Artística, tanto em sala de aula quanto fora dela, como recurso psicopedagógico a ser utilizado na Pré-scola e Ensino de $1^{\circ} \mathrm{Grau}$. Na parte da Música, o objetivo é “evidenciar o processo ensino-aprendizagem, mostrando aspectos relativos ao conteúdo a ser trabalhado e ao desenvolvimento da sensibilidade, 
principalmente, para as classes pré-escolares e para séries iniciais do $1^{\circ} \mathrm{Grau}$ ".

Como introdução ao trabalho de Música, o documento expõe sua base teórica sobre como compreende as experiências essenciais ao desenvolvimento infantil, enfocando a importância da criança vivenciar situações, descobrir e movimentar o corpo, manipular objetos, perceber e construir conceitos, estabelecer relações e realizar atividades de coordenação motora e discriminações auditivas entre outras. A referência bibliográfica geral traz obras de Benjamin Bloom "Taxionomia dos objetivos educacionais" (1974), Hans Furth "Piaget na sala de aula" (1976); Michaelis, John U. ; Grossman, Ruth H. ; Scott, Lloyd F. "Nuevos diseños para el currículo de la escuela; Ana Maria Poppovic “Alfabetização - Disfunção Psiconeurológicas (1975) e outros subsídios em circulação na rede pública. Na área da música não há autor referendado.

Ainda fundamentando a proposta de trabalho, o documento apresenta a discriminação auditiva como importante elemento auxiliar da percepção temporal e por esse motivo deve promovê-la propiciando situações de trabalho com diferentes sons da natureza de do meio ambiente, enfocando a duração, intensidade, timbre e altura dos sons. Cita as atividades de ouvir música, imitar sons, cantar e expressar-se, melódica e ritmicamente, improvisar, criar, explorar objetos que produzem sons como "atividades que poderão 
oportunizar à criança o desenvolvimento de habilidades psicomotoras imprescindíveis à alfabetização, além de socializá-la e concorrer para seu ajuste fisco e emocional" (p.2). Dando continuidade às considerações básicas, 0 documento considera importante as atividades cantadas, mas as considera insuficientes para promover todas as potencialidades que a música oferece. Recomenda vivências rítmicomelódicas, e o preparo físico e muscular através do relaxamento para as atividades que visam o desenvolvimento da observação e da atenção. Segundo as orientações, o aprendizado de canções e a apreciação musical será uma consequência da atenção dada a esses aspectos anteriormente trabalhados.

No Projeto PRODIARTE, a partir de atividades musicais o aluno é trabalhado nas áreas da Percepção, Motricidade, Esquema Corporal e Criatividade.

O Conteúdo Musical é definido a partir da Estrutura da Música, identificada como composta de Som, Ritmo e Melodia, está organizado em 4 etapas distribuídas tendo em consideração as habilidades intelectuais implicadas nas atividades musicais. No sentido vertical, o Conteúdo Musical enfoca as habilidades intelectuais para identificar, comparar, classificar, aplicar e produzir criativamente. A partir dessas habilidades, tomadas como níveis de conteúdos e objetivos da etapa do trabalho musical, as atividades musicais são organizadas em sentido horizontal, 
segundo sua complexidade ou aprofundamento. Assim, cada elementos da estrutura da música Som, Ritmo e Melodia, tomados como conteúdos a serem trabalhados, são detalhados e graduados tendo em vista a sua complexidade na forma de realização. Tomando como exemplo - conteúdo Ritmo, este será trabalhado inicialmente a capacidade de identificar e reconhecer e nomear na etapa I e II da Educação Musical. Para as etapas III e IV, as habilidades de comparar, aplicar e produzir criativamente os ritmos deverão nortear as atividades.

O desenvolvimento do conteúdo referente ao Som, o qual abrange o trabalho com os parâmetros sonoros altura intensidade, duração e timbre, é abordado inicialmente como identificação, nomeação, enumeração $e$ agrupamento dos sons da natureza e do ambiente, para em seguida ser conduzido a perceber os parâmetros sonoros. Da mesma forma, os parâmetros sonoros são trabalhados considerando-se sempre as habilidades intelectuais implicadas na atividade. As habilidades de aplicar e produzir criativamente, por exemplo, não figuram como objetivos nos níveis iniciais da Educação Musical.

No final do documento é apresentada uma relação de canções folclóricas, distribuídas em 4 grupos, conforme as etapas de trabalho previstas.

Observa-se nesse documento um trabalho bastante complexo tratando de compatibilizar os conteúdos musicais, extraídos da Estrutura da 
Música, com as habilidades intelectuais dos estudantes. 0 marco teórico do documento revela a intenção da Secretaria de Educação do Rio Grande do Sul em estender para a área artística a linha vigente da educação geral.

\section{Consideraçoes finais}

A primeira impressão sobre a Educação Musical nas escolas públicas do Rio Grande do Sul é de que nunca foi tomada alguma providência no sentido de definir metas e fundamentar linha teórica. Os documentos analisados nos mostram que a Educação Musical, em certo momento histórico, teve uma linha bem delineada e implementada pelo governo estadual. A Educação Musical que hoje se pratica nas escolas da rede pública guarda alguma semelhança com os estudos aqui apresentados, mostrando que aquilo que foi implementado subsistiu ao tempo e firmou-se como senso comum.

Para um estudo bibliográfico mais aprofundado sobre os objetivos, conteúdos e práticas mais comuns empregadas em décadas passadas nas escolas do RS, seria interessante incluir na análise os livros mais difundidos nas escolas. Como sabemos, as publicações didáticas funcionaram como substituto de orientações oficiais, sugerindo aos professores de todas as áreas, não apenas os conteúdos a serem desenvolvidos, mas sua distribuição por série e 
forma de avaliação. Um livro que poderia ser muito elucidador é "O ouvinte Consciente" de Sérgio Corrêa, publicado pela Editora Brasil, pois no ano de sua publicação (1975) alcançou sete edições, permanecendo nas escolas pelo menos mais uma década. Outra obra de grande circulação nas escolas foi "Música na Escola Primária” de Edna Valle e Niobe Marques Costa, publicado pela Editora Olympio possivelmente na década de 60 . Esse livro teve alta vendagem e foi dedicado à didática da música. É uma obra interessante de ser analisada, em vista de tantas sugestões de "como" desenvolver os conteúdos musicais. A editora Ática tem no mínimo duas obras de muita circulação: "Educação Artística - Primeiro Grau" de Glorinha Aguiar e “Educação Artística Plástica e Música" de Marieta Nicolau.

Manuseando os livros didáticos disponíveis, observei que não costuma constar o ano de publicação, apenas a edição. Omitindo esse detalhe, as editoras podem reimprimir inúmeras vezes, sem que a obra figure como desatualizada ou antiga. Nesse caso, somente pelas datas das obras indicadas na bibliografia se pode ter uma idéia aproximada do período de publicação.

Não foi objetivo desta comunicação fazer uma crítica às propostas estudadas, no entanto considero de grande importância, até mesmo imprescindível, que os mesmos documentos sejam alvo de críticas fundamentadas 
teoricamente, a fim de que possamos aprender a partir das experiências já realizadas.

\section{Referências bibliográficas}

AGUIAR, Glorinha. Educação Artística. Primeiro grau. São Paulo: Ática, 1980.

CORRÊA, Sérgio Ricardo. O ouvinte consciente. $7^{\circ}$ ed. São Paulo: Editora do Brasil, 1975.

GOVERNO DO ESTADO DO RIO GRANDE DO SUL. Secretaria de Educação. Educação Artística Cadernos de Orientação. 1978

Projeto Especial:

Desenvolvimento Integrado da Arte na Educação. PRODIARTE. Subsídio de Orientação $n^{\circ} 2,1981$

NICOLAU, Marieta. A Educação Artística da Criança. Plástica \& Música.

Fundamentos e Atividades. São Paulo: Ática, 1986.

VALLE, Edna Almeida e COSTA, Niobe Marques. Música na Escola Primária. Rio de Janeiro: Editora Olympio, s/d. 